\title{
An Electronic Textbook as a Means of Improving the Quality of Student Learning at the University
}

\author{
Marina G. Sergeeva ${ }^{1 *}$, Azer A. Aliev ${ }^{1}$, Tatiana Yu. Tsibizova ${ }^{1}$, and Anna D. Pravdina ${ }^{1}$ \\ ${ }^{1}$ Bauman Moscow State Technical University, 2nd Baumanskaya str., 5/1, 105005, Moscow, Russia
}

\begin{abstract}
The origin and development of e-learning methods in Russia and other countries is due to steady progress in the field of information and communication technologies and the general informatization of the educational process, the creation of a global environment for the mutual integration of cultures and disciplines, as well as the establishment of continuing open-ended education that underlies post-industrial (information) society. Under the influence of these processes, there is a need for new, more advanced educational practices, which is the reason for the transformation of both the essence of national education and its formal side. Nowadays, a person should possess not only a certain amount of useful information, but also the ability to learn: search and find the necessary information, use various sources to get out of difficult situations, continuously expand the range of one's own competencies, and constantly develop, keeping up with what is happening around. In the framework of the modern educational paradigm, the student is considered as a subject of knowledge, and not an object of pedagogical influence. In the early to mid2010 s, active contribution to this is made by e-learning (electronic learning, e-learning), which must be used in educational institutions of various types and at different levels of the educational vertical. It makes it possible to integrate into the global scientific community, to become subjects of the interaction of cultures, including the exchange of spiritual values. The introduction of e-learning is one of the key tasks in the context of the modernization of national education. The term «electronic learning» is transmitted into Russian in various ways. The most popular options are: "distance learning / education", "mobile learning", "virtual learning". The European Commission interprets "e-learning" as "the use of new multimedia and Internet technologies to improve the quality of education by improving access to resources and services, as well as remote knowledge sharing and collaboration". In this study, the term "e-learning" will correspond to the phrase "electronic learning". This is a learning process based on interactive electronic means of storing and providing information: the Internet, corporate networks, and CD-ROMs.
\end{abstract}

\footnotetext{
* Corresponding author: sergeeva198262@mail.ru
} 


\section{Introduction}

The country's competitiveness in the modern world is an important indicator of the development of the state and a guarantee of national security. Currently, Russia is actively introducing information technologies in all spheres of society through the organization of a number of national projects, the most important of which include the national project "Education", adopted in December 2018 and designed to ensure the competitiveness of Russian education, as well as withdraw the Russian Federation in the top ten leading countries in terms of the quality of education by 2024 . One of the objectives of the project is "the creation by 2024 of a modern and safe digital educational environment that ensures high quality and accessibility of education of all types and levels" and "the modernization of vocational education" $[1,2]$. Currently, the process of teaching at universities is taking place in the information and educational environment (IEE), the basis of which is various educational resources: electronic libraries, video and online courses, electronic textbooks. By an electronic textbook (ET) we mean «a digital learning tool that contains a systematic and complete exposition of the subject or part of it, ensuring the completeness of the didactic cycle of the learning process, creating an individualized active-educational educational environment».

Since 2017, there is an information portal created within the framework of the priority project "Modern Digital Educational Environment in the Russian Federation", which brings together more than 30 online educational platforms in the "single window" mode, more than 120 universities; more than 1000 online courses are currently registered in the portal. An analysis of the content of this information portal and the information portals of individual universities showed the absence of electronic textbooks that would fully meet the above definition, while they could reduce the routine of teachers by automating student performance monitoring during the semester, provide full feedback and be used not only for selfeducation, but also be included in the educational process of the university.

\section{Historical review}

In accordance with the Federal Law "On Amending the Law of the Russian Federation "On Education in the Russian Federation" regarding the use of e-learning and distance learning technologies" (February 28, 2012, No. 11-FZ), e-learning is defined as the organization of the educational process using: (1) the information contained in the databases and used in the implementation of educational programs; (2) information technologies and technical means providing the processing of this information; and (3) information and communication networks, through which the necessary data are transferred via communication lines and the interaction of participants in the educational process.

Formally, Russian distance education arose in 1992, on the day of the adoption of the «Concept for the creation and development of a unified system of distance education to increase the availability and quality of training programs throughout the country». After a while, a number of large universities introduced early models of distance learning systems. Nevertheless, in Russia, unlike the United States and European countries, computerization was so low that electronic education should be treated more like distance extramural learning. The last decade of the 20th century was characterized by increased attention to testing programs, presentations, and the development of electronic textbooks. Experts in the field of computer technology created the first software products that form the conditions for distance interaction between teachers and students. In the 2000s, EE began to actively integrate into traditional education in a wide variety of formats: as a support for traditional education (intramural and extramural), as a higher level of distance education in accordance with the programs of first and second higher education, advanced training, additional education and 
pre-university training $[3,4]$. On the eve of the new decade, a draft of "Concept of the Federal Law "On the E-Learning Industry" was created in our country. Its main tasks were the planning and implementation of scenarios for improving the e-learning sector in the Russian Federation, and the main goal was the legal support of this

Programs aimed at supporting e-learning by law are being developed in more than 30 countries. In developed countries, even those educational institutions that have existed for more than one century have begun to perceive the presence of online courses in their educational programs as a prerequisite for effectiveness $[5,6]$. So, in the USA distance education methods are offered in two hundred universities and thousands of colleges, in which more than 3 million people study. Many of the world's largest universities provide free online courses: University of California, Massachusetts Institute of Technology, Open British University ("OpenLearn" program), and so on. The "Coursera" project developed in 2011 can be cited as a striking example. It immediately combined the online resources of the three leading American universities, which are in the public domain, and after about ten months (less than a year!), Time magazine recognized this educational site as the best in 2012. According to statistics, about 1 million people became project listeners in the first six months alone, and by 2013 the number of registered users had grown almost two and a half times (2.3 million). At the same time, the number of participating countries almost reached two hundred. Coursera currently partners with 33 universities. In the spring of 2013, a joint project was launched with the domestic private company Digital October, aimed at creating Russian-language subtitles for the Coursera courses to make learning as convenient as possible for our students.

Abroad, more than 100 million people turn to distance education. According to experts, this sector of the educational services market will only grow - both in depth and in breadth. International experience indicates that when using well-developed educational programs and a thoughtful training course, the effectiveness of EE is often not lower than traditional forms of training $[7,8,9]$. It is recognized by such authoritative organizations as the $\mathrm{UN}$ and UNESCO. According to some experts, approximately $70 \%$ of university students prefer elearning abroad. In our country, there are still few such students. A list of Russian institutes, academies and universities offering distance education is available at http://edu.rin.ru/. In the Russian Federation, this approach to learning is becoming very relevant in the context of the implementation of the new generation of federal state educational standards (FSES), a tiered education system and the resulting reduction in the classroom load and the creation of favorable conditions for students to work independently (for which the electronic format seems optimal). Curricula designed for foreign clients, the growing number of students studying abroad, as well as the strategic use of international networks, speak of the desire of domestic distance education to enter the world level $[10,11]$.

Information processes in education are part of the global transition to the information society. The implementation of the capabilities of information and communication technology (ICT) tools in the field of education is being carried out by informatization, the branch of pedagogical science, which is considered as a purposefully organized process of providing the education sector with the methodology, theory, technology and practice of developing and optimizing the use of ICT tools used in comfortable and health-saving conditions.

Modern approaches to formalizing educational knowledge can help optimize the structure of educational material. In contrast to the traditionally presented educational material in the form of linear structures, the hypertext presentation of educational information can significantly increase the volume of the material, expanding the subject and range of its presentation, facilitating the search, interpretation, and selection of the desired aspect [12]. The improvement of methodological training systems is characterized by the creation of pedagogical technologies, methodological training systems focused on the formation of 
information competence. In this case, pedagogical goals are determined by the possibility of implementing intensive forms and methods of learning, increasing the motivation of learning through the information-intensive and emotional communication of the user with virtual objects and the formation of skills to implement various forms of independent activity with the Internet resource.

\section{Proposed Methodology}

Recent studies have presented the didactic features of an electronic textbook as a source of educational content. The main feature of the electronic textbook is that it includes not only the content of education, but also the chosen learning technology. An electronic textbook is an automated educational system that includes didactic, methodological, and informational and reference materials on the academic discipline, as well as software that allows you to use them comprehensively for independent acquisition and control of knowledge [13, 14]. Below are the features of building an electronic textbook.

Firstly, in an electronic textbook information is formed in the form of hypertext. Hypertext is the ability to create a «live», interactive educational material, provided with reciprocal links to various parts of the material. Hypertext makes it possible to divide the material into a large number of fragments, connecting them with hyperlinks in logical chains.

Secondly, in the electronic textbook there is the possibility of using multimedia - a rich arsenal of ways to illustrate the phenomenon under study. Multimedia products use diverse varieties of information: computer data, television and video information, speech and music. Multimedia is interactive in nature, that is, the viewer and listener of multimedia products does not remain passive. Multimedia improves the quality of learning and allows you to keep the learner's attention.

Thirdly, the electronic textbook allows you to use the modeling of the processes and phenomena studied, the ability to conduct «computer experiments» in those areas of human knowledge where real experiments are very time-consuming or simply impossible. The presence of a system of self-knowledge, a system of midterm control, compatibility with an electronic examination system. The ability to evaluate acquired knowledge.

An electronic textbook differs from a traditional textbook in a different organization of educational content. So, the electronic textbook provides:

- shrinkage of the text of the chapter, so that it is easier to read on the screen;

- dividing the material into several contexts (for example, obligatory for reading, additional, auxiliary, definitions, etc.);

- separation of the content of educational material into modules, in accordance with the requirements of psychologists;

- the succinctness and brevity of the material with maximum information content of the text,

- the inclusion of graphic software, which allows to transfer the necessary amount of information with the brevity of its presentation.

Describing the situation of informatization of education in Russia, scientists state: pedagogical practice is ahead of pedagogical theory, information and communication technologies permeate all aspects of the professional life of teachers, which contributes to the activation of the creative activity of those who are able to apply innovative teaching methods and effectively use ICT to achieve pedagogical goals. Among the factors hindering the mass use of ICT tools in domestic education, the following are noted: the absence of content elements oriented towards the use of ICT tools in the traditional textbooks; lack of ICT application methods in a specific educational situation; lack of integration of most software tools in the educational context. 
Guided by the need to implement various scenarios for using an electronic textbook, the following structural units of an electronic textbook are distinguished: 1) the main material, equipped with explanatory texts, interactive illustrations, including theoretical provisions and a set of typical tasks; 2) additional materials in the form of audio and video fragments, cognitive materials that reveal the history of scientific thought, methods of scientific knowledge, etc.; 3) the practical part, consisting of creative tasks blocks on the student's choice that test, teach and control the level of assimilation of educational material; 4) a block of statistical information on the results of the use of electronic textbooks by students; 5) a block of means for assessing the complexity of tasks, the level of assimilation of educational material by students.

A graph-oriented approach is proposed to build individual learning paths and ensure the variability of personal tasks. The essence of the graph-oriented approach is to structure the content into various sections, ranked according to the logic of studying the course, and to provide each element of the content with a numerical indicator of its implementation complexity. The initial values of the complexity indicators can be determined by experts or experimentally, then adjusted automatically or by the teacher, depending on the level of students' knowledge, thus giving the textbook adaptive properties. To solve the problems of forming various individual tasks of the same complexity level and building individual learning paths that take into account the level of students' knowledge, you can use the methods of mathematical graph theory. At the vertices of the oriented content graph are the elements (tasks, various tests, theoretical positions, creative tasks, etc.), the direction of the arcs determines the sequence of passage of these elements, and the branch points bring the learning process in accordance with the student's personality. In this case, each training trajectory is modeled as a path in a graph, for the search of which well-known mathematical methods can be used. Thus, the graph-oriented approach allows us to formulate two didactic principles of designing an electronic textbook:

- the didactic principle of the formation of individual educational trajectories by means of a graph-oriented approach;

- the didactic principle of adaptability of an electronic textbook, implemented on the basis of feedback and statistical processing of user results.

The electronic textbook is considered as the core of the modern educational and methodological complex, which also includes the traditional print publication. Interconnected requirements for the printed edition and the electronic version of the textbook are proposed, including the separation of theoretical material into small parts, the block structure of the material, a large number of typical tasks that are used as hints for organizing the self-learning process, the presence of the most complete glossary that allows you to use the electronic textbook as a reference with using hyperlinks.

\section{Result Analysis}

Our empirical study was carried out in the specialized economic classes of Moscow schools, which made contracts with universities conducting vocational guidance pre-university training, for the education of prospective university students.

Let us consider which textbook series are suitable for integration with information and communication technologies and can be taken as the basis for the model of economic education. Social studies textbooks are developed by humanitarian scientists. Textbooks on economics are developed by economists. Social studies textbooks have a predominantly descriptive presentation style. Focusing on humanities teachers, the authors of these textbooks avoid analytical (mathematical) and graphical forms of presentation of educational material. At the same time, it becomes difficult to fully examine macro- and microeconomic models: content elements, key economic concepts are given fragmentarily, in isolation from 
their relationships: functional, logical, hierarchical, etc. These textbooks are not sufficiently illustrated by schemes, poorly structured, which in fact does not correspond to modern economic theory. As a result, the prevalence of the reproductive form prevails, since for independent productive activity, students would have to get an idea of the objective relationships of economic concepts and dependencies expressed by formulas. From the point of view of study topic, we can conclude that the imposition of ICT on such a structure of the content seems ineffective, since it will require a lot of additional refinement.

Textbooks on economics written by economists, not educators, are difficult for senior students to perceive (let us note, they are also difficult for humanitarian teachers); they have a predominantly transferable character, poorly take into account the characteristics of the Russian economy. At the same time, they are well-structured, which allows illustrating macro- and microeconomic models, their elements and basic connections using modern multimedia; present material in both analytical and graphical form. The content structure of such textbooks, in our opinion, is more consistent with the architecture of the electronic textbook, which involves the use of multimedia and hypertext, the division of content into separate modules without violating the logic of studying the content $[17,18]$.

Let us further consider the teaching methods used in the lessons of economics. Let us turn to the best practices of economic teachers who widely apply the so-called innovative methods and highly value their effectiveness. So, the following forms and methods of training are recognized as effective: a business game, computer modeling, problematic discussion, testing, training, seminar, preparation of essays, organization of school companies $[17,18$, 19]. However, the majority of teachers, as shown by an analysis of the questionnaire results, even today, after twenty years, do not have a sufficient idea of innovative teaching methods, including one of the fastest-changing disciplines - economics [20, 21]. Moreover, in the practice of teaching economic content there is a certain imbalance between the demand for, relevance of economic knowledge and the level of economic training of teachers of social studies (economics). Highly appreciating the importance of the economic sphere, teachers extremely low assess the level of their own training in economics, the level of knowledge of modern teaching methods. The data obtained indicate that $90 \%$ of the teachers surveyed recognized the importance of studying economics in high school. At the same time, only $38 \%$ of social science teachers consider themselves trained in economic matters. The number of respondents also included teachers of economics, whose average level of training in economic theory is not much higher than the average in social science. In table 1, the topics of the course «Social Studies» are ranked as the proportion of teachers who consider themselves fully prepared for their teaching decreases.

Table 1. The level of teacher training in content lines of social studies.

\begin{tabular}{|c|c|}
\hline Sections of the Social Studies course & $\begin{array}{c}\text { \%o of respondents who consider themselves fully } \\
\text { trained on this topic }\end{array}$ \\
\hline Political science & 73 \\
\hline Law & 69,5 \\
\hline Sociology & 67,5 \\
\hline Cultural science & 61 \\
\hline Global world & 55 \\
\hline Information society & 53 \\
\hline Philosophy & 45 \\
\hline Economics & 38,5 \\
\hline Religious Studies & 38,5 \\
\hline Social Psychology & 37 \\
\hline
\end{tabular}

Insufficiently mastering the methodological tools necessary for studying economics at the modern level, teachers in mass practice are forced to rely mainly on the lecture form of classes. Teachers unanimously speak out about the need for changes in the continuing education system. Even taking into account that the self-esteem of teachers is subjective and 
can be both overstated and underestimated, such statistics indicate the need to pay attention to the opinion of teachers.

\section{Conclusion}

However, e-learning and information technology will not be able to completely replace the classical form of education in general and the teacher in particular. It is necessary to modernize the ways of student-teacher interaction, their contribution to the educational process. According to experts, modern information and communication technologies do not create sufficient conditions for live communication between the teacher and the student. Blended learning that combines the principles and technologies of distance education with classical, classroom studies, seems more promising. For example, the information received by students in the process of working with materials of the online course can be the subject of discussion at relevant seminars, as well as applied within practical disciplines or when writing research papers. In this context, it should also be noted that even those students who are more digitally savvy do not always prefer an electronic textbook. Thus, well-organized e-learning is one of the most important conditions for the innovative development of the educational system in general and higher education in particular. Balanced EE, which is an addition to the traditional form of knowledge transfer, should be perceived as the main vector of the education system in the context of globalization, widespread Internet, as well as bringing services and technologies closer to the needs of society. Electronic education can become one of the effective ways to eliminate or at least weaken the isolation of the domestic educational system. Activities based on the use of online resources have a high efficiency potential and are in high demand in the modern educational services market (compared to other forms of training). For this reason, e-learning, which involves the attraction of network resources, is causing increasing public interest.

\section{References}

1. A.A. Aleksandrov, Fang Ke, A.V. Proletarsky \& K.A. Neusypin, Conception complex continuous education with innovative information technologies, Proceedings of 2nd International Conference on Education and Education Management (EEM 2012), pp. 374-378 (2012). Retrieved from www.scopus.com

2. L.V. Gaidarenko, O.A. Isabekova, P.A. Kapyrin, N.A. Meshkov \& A.E. Popovich, Innovation development concept of the Russian educational complex in the conditions of information society, Astra Salvensis, 6, pp. 723-734 (2018). Retrieved from www.scopus.com

3. I. Kmecová, Digitization, Digital Technology, and Importance of Digital Technology in Teaching, Lecture Notes in Networks and Systems, 84, p. 526-537. Retrieved from www.scopus.com

4. D.V. Drobyshev, K.A. Neusypin \& T.Yu. Tsibizova, Distance education in the training system of highly qualified personnel, AIP Conference Proceedings 2195, 020066 (2019); https://doi.org/10.1063/1.5140166. Retrieved from www.scopus.com

5. A.A. Gibb, Exploring the synergistic potential in entrepreneurial university development: Towards the building of a strategic framework, Annals of Innovation \& Entrepreneurship, 3, pp. 1-24 (2012). Retrieved from www.scopus.com

6. Q. Jian, Effects of digital flipped classroom teaching method integrated cooperative learning model on learning motivation and outcome, Electronic Library, 37(5), pp. 842859 (2019). Retrieved from www.scopus.com 
7. S. Arunkumar, S. Sasikala \& K. Kavitha, Towards enhancing engineering education through innovative practices in teaching learning, International Journal of Engineering and Advanced Technology, 8, pp. 153-159 (2018). Retrieved from www.scopus.com

8. S.N. Sailin \& N.A. Mahmor, Improving student teachers' digital pedagogy through meaningful learning activities, Malaysian Journal of Learning and Instruction, 15(2), pp. 143-173 (2018). Retrieved from www.scopus.com

9. T.P. Skorikova, S.S. Khromov \& N.V. Dneprovskaya, Distance learning in scientific and professional fields of communication (interdisciplinary approach), International Journal of Environmental and Science Education, 11(10), pp. 3467-3476 (2016). Retrieved from www.scopus.com

10. P. Svoboda, Digital technology as a significant support for the teaching process, Intelligent Systems and Computing, 1018, pp. 383-389 (2020). Retrieved from www.scopus.com

11. T. Nousiainen, M. Kangas, J. Rikala \& M. Vesisenaho, Teacher competencies in gamebased pedagogy, Teaching and Teacher Education, 74, pp. 85-97 (2018). Retrieved from www.scopus.com

12. T.Yu. Tsibizova, V.M. Postnikov \& S.B. Spiridonov, Analysis of the impact of technology lectures-visualizations on the results of control measures in various academic disciplines, Perspektivy Nauki I Obrazovania, 33(3), pp. 358-363 (2018). Retrieved from www.scopus.com

13. M.F. Alcibar, A. Monroy \& M. Jiménez, Impact and use of information and communication technologies in higher education, Informacion Tecnologica, 29(5), pp. 101-110 (2018). Retrieved from www.scopus.com

14. M.G. Sergeeva, Y.A. Chighovskaya-Nazarova, S.V. Dmitrichenkova, S.Y. Papirovskaya V. A. Chauzova \& I. S. Andryushchenko, Effectiveness verification of the application of imitation methods of education in the training of a specialist, Espacios, 39(38), p. 11 (2018). Retrieved from www.scopus.com

15. C. Lorenzo \& E. Lorenzo, Opening Up Higher Education: An E-learning Program on Service-Learning for University Students, Intelligent Systems and Computing, 963, pp. 27-38. Retrieved from www.scopus.com

16. A.S. Burlea \& D.D. Burdescu, An integrative approach of E-learning: From consumer to prosumer, Smart Innovation, Systems and Technologies, 59, pp. 269-279 (2016). Retrieved from www.scopus.com

17. M.G. Sergeeva, N.N. Bedenko, T.Yu. Tsibizova, M.S. Mohammad Anwar \& T.G. Stanchuliak, Organisational economic mechanism of managing the growth of higher education services quality, Espacios, Vol. 39 (\# 21), p. 10 (2018). Retrieved from www.scopus.com

18. M.G. Sergeeva, N.N. Bedenko, L.Z. Karavanova, T.Yu. Tsibizova, I.S. Samokhin \& M.S. Mohammad Anwar, "Educational Company» (technology): Peculiarities of its implementation in the system of professional education, Espacios, Vol. 39(2), p. 24 (2018). Retrieved from www.scopus.com

19. A.A. Aleksandrov, P.A. Kapyrin, N.A. Meshkov, K.A. Neusypin, A.E. Popovich \& A.V. Proletarsky, Gamification in the advanced higher professional education: fundamentals of theory and experience of use, International Journal of Civil Engineering \& Technology (IJCIET), Vol. 9, I. 11, pp. 1800-1808 (2018). Retrieved from www.scopus.com

20. S.A. Gudkova, T.S. Yakusheva, A.A. Sherstobitova \& V.I. Burenina, Modeling of scientific intercultural communication of the teaching staff at smart university, Smart 
Innovation, Systems and Technologies, 144, pp. 551-560 (2019). Retrieved from www.scopus.com

21. S.A. Gudkova, T.S. Yakusheva, A.A. Sherstobitova \& V.I. Burenina, Modeling, selection, and teaching staff training at higher school, Smart Innovation, Systems and Technologies, 144, pp. 619-629 (2019). Retrieved from www.scopus.com 